\title{
Um caso de Nefrite de shunt associada a elevação transitória de anticorpos anti-dsDNA
} A case of shunt nephritis associated with transient elevation of anti-dsDNA

\author{
Marta Soares ${ }^{1}$, Cristina Rosário ${ }^{1}$, Sandra Silva ${ }^{2}$, Estela Ramos ${ }^{1}$ \\ ${ }^{1}$ Serviço de Medicina Interna. 2 Unidade de Nefrologia. Hospital Pedro Hispano. Matosinhos. Portugal
}

\section{Resumo}

A relação entre doenças autoimunes e infeção está bem descrita na literatura. No entanto, desconhece-se qual o mecanismo patofisiológico envolvido nas infeções para o desenvolvimento de autoimunidade. Por outro lado, existem infeções que cursam transitoriamente com positividade para alguns autoanticorpos sem nenhuma evidência de doença imunológica.

A nefrite de shunt (NS) é uma glomerulonefrite mediada por imunocomplexos que surge habitualmente associada a infeção de shunt ventrículoauricular. Raramente, a NS pode-se acompanhar de marcadores imunológicos positivos como os anticorpos antinucleares e anti-citoplasma dos neutrófilos (ANCA). Contrariamente, os anticorpos anti-DNA de cadeia dupla (anti-dsDNA) são reconhecidos pela sua especificidade para o diagnóstico de lúpus e desconhecem-se relatos prévios da sua associação a NS.

Os autores apresentam o caso de uma NS com positividade tanto para os ANCA-PR3 como para os anti-dsDNA em que não houve manifestação de doença autoimune e em que a resolução da infeção levou à descida paulatina dos autoanticorpos.

Palavras-chave. Nefrite; Glomerulonefrite; Shunt; Autoimunidade; AntidsDNA; ANCA

\section{Introdução}

As doenças autoimunes surgem, habitualmente, como resultado da combinação de diversos factores, nomeadamente genéticos, imunológicos, hormonais e ambientais, compreendendo a conhecida designação de "mosaico da autoimunidade". Dentro dos factores ambientais, as infeções desempenham um papel preponderante, estando amplamente descrita na literatura a relação entre infeção e autoimunidade ${ }^{1}$. Por outro lado, a positividade transitória de autoanticorpos durante infecções agudas, sem evidência de doença imunológica, é também conhecida².

A nefrite de shunt (NS), descrita pela primeira vez por Black et al em 1965, é uma glomerulonefrite mediada por imunocomplexos ${ }^{3}$. Ocorre geralmente em doentes com infeção de shunts ventrículo-auriculares implantados por hidrocefalia adquirida ou congénita ${ }^{4}$. A sua incidência é baixa, estimando-se que surja em apenas 0,7\% a 2,25\% dos doentes com infeção do shunt ${ }^{5}$. Ocasionalmente, esta entidade associa-se à presença de marcadores imunológicos que desaparecem após a resolução da infeção $0^{6,7}$. Os anticorpos anti-citoplasma dos neutrófilos (ANCA) são, frequentemente, positivos em variadas doenças autoimunes, existindo inclusive relatos da sua positividade em

\begin{abstract}
The relationship between autoimmune disease and infection is well known in literature. However, the pathophysiologic role of infections in the development of autoimmunity is largely unknown. Furthermore, there are infections that occur with transient autoantibody positivity without any evidence of immunologic disease.

Shunt nephritis (SN) is an immune complex mediated glomerulonephritis usually related with infection of ventriculoatrial shunt. Rarely, SN may be accompanied by positive immunological markers, like antinuclear and anti-neutrophil cytoplasm (ANCA) antibodies. In contrast, antibodies to double-stranded DNA (anti-dsDNA) are recognized by their specificity for the diagnosis of lupus, and have never been described in association with SN. The authors present the case of a NS with positivity for both PR3-ANCA and for anti-dsDNA in which there was no manifestation of autoimmune disease and the resolution of the infection led to the gradual decline of autoantibodies.
\end{abstract}

Key words: Nephrite; Glomerulonephritis; Shunt; Autoimmunity; AntidsDNA; ANCA

casos de NS ${ }^{6,7}$. Contrariamente, os anticorpos anti-DNA de cadeia dupla (anti-dsDNA) têm elevada especificidade para 0 diagnóstico de lúpus eritematoso sistémico $(\mathrm{LES})^{8}$ e só muito raramente surgem noutras doenças autoimunes. Nestes casos excepcionais a sua presença acrescenta complexidade ao raciocínio diagnóstico.

Os autores apresentam o caso de uma glomerulonefrite associada a infeção de shunt ventrículo-auricular com positividade tanto para os ANCA-PR3 como para os anti-dsDNA.

\section{Caso Clínico}

Os autores apresentam o caso de uma mulher de 46 anos que recorreu ao serviço de urgência por um quadro, com 1 semana de evolução, de tosse seca e lesões purpúricas ao nível dos membros inferiores associadas a edema; nos dois dias prévios foi documentada febre. Referia ainda astenia e emagrecimento de agravamento progressivo desde há vários meses. Sem outras queixas.

Trata-se de uma doente com uma malformação ao nível da fossa posterior com hidrocefalia, identificada aos 11 anos de idade, que obrigou à colocação de derivação ventrículo-auricular. Seguida regularmente por neurocirurgia e sem intercorrências descritas. Aos 45 anos houve necessidade de substituir o shunt e optou-se por colocar um shunt ventrículo-peritoneal. A remoção não foi, no 
Tabela 1. Estudo analítico na admissão e após 8 meses.

\begin{tabular}{|c|c|c|c|}
\hline & $\begin{array}{l}\text { Valor de } \\
\text { referência }\end{array}$ & Internamento & $\begin{array}{l}\text { Após } 8 \\
\text { meses }\end{array}$ \\
\hline \multicolumn{4}{|l|}{ Hemograma e Bioquímica } \\
\hline Hemoglobina & 12-16g/dL & 7,7 & 13,7 \\
\hline VGM & 80-100fl & 65 & 83,4 \\
\hline HGM & $26-34 \mathrm{pg}$ & 21,4 & 29,2 \\
\hline Leucócitos & 4.0-11.0Еxp3/UL & 11.2 & 6.2 \\
\hline Plaquetas & 150-400Ехx3/UL & 240 & 224 \\
\hline Glicose & $70-105 \mathrm{mg} / \mathrm{dL}$ & 105 & 87 \\
\hline Ureia & $15-40 \mathrm{mg} / \mathrm{dL}$ & 25 & 43 \\
\hline Creatinina & $0,6-1,1 \mathrm{mg} / \mathrm{dL}$ & 0,8 & 0,8 \\
\hline $\mathrm{Na}+$ & 136-145mEq/L & 130 & 142 \\
\hline$K_{+}$ & 3,4-5,1mEq/L & 3,4 & 4,5 \\
\hline Proteínas totais & 6,4-8,3mg/dL & 7,3 & 7,8 \\
\hline Albumina & $3,5-5,0 \mathrm{mg} / \mathrm{dL}$ & 2,9 & 4,6 \\
\hline PCR & $<0,5 \mathrm{mg} / \mathrm{dL}$ & 10,8 & - \\
\hline \multicolumn{4}{|l|}{ Análise urina } \\
\hline Albumina & 0 & 200 & 0 \\
\hline Leucócitos & $<5$ & $10-25(x 400)$ & 2 \\
\hline Eritrócitos & $<2$ & $5-10(\times 400)$ & $<1$ \\
\hline Cilindros & & Hialinos, granulosos e celulares & 0 \\
\hline Proteinúria 24h & & $938 \mathrm{mg}$ & - \\
\hline \multicolumn{4}{|l|}{ Estudo imunológico } \\
\hline Anticorpos anti-nucleares & & 1:320 & $1: 160$ \\
\hline Anticorpos anti-dsDNA & $<10 \mathrm{U} / \mathrm{mL}$ & 146 & 28 \\
\hline ANCA-PR3 & $<7 \mathrm{U} / \mathrm{mL}$ & 160 & 0,3 \\
\hline ANCA-MPO & $<7 \mathrm{U} / \mathrm{mL}$ & 2,0 & - \\
\hline Fator reumatóide & $<30 \mathrm{U} / \mathrm{mL}$ & 52,4 & 20 \\
\hline Complemento C3 & 83-193mg/dL & 75,0 & 107 \\
\hline Complemento C4 & $15-57 \mathrm{mg} / \mathrm{dL}$ & 11,9 & 30,7 \\
\hline $\lg G$ & $552-1631 \mathrm{mg} / \mathrm{dL}$ & 2535,0 & 1155 \\
\hline $\lg A$ & $65-421 \mathrm{mg} / \mathrm{dL}$ & 293,0 & 143 \\
\hline $\lg M$ & 32-293mg/dL & 611,0 & 342 \\
\hline Velocidade sedimentação & $0-20 \mathrm{~mm} / 1 \mathrm{H}$ & 80 & 16 \\
\hline Título anti-estreptolisina 0 & $<200 \mathrm{U} / \mathrm{mL}$ & 71,8 & - \\
\hline
\end{tabular}

entanto, total, pela presença de aderências, e manteve-se a porção inferior, entre a veia jugular e a aurícula direita. Tinha história prévia de alergia à penicilina.

Ao exame objetivo na admissão documentou-se febre (temperatura auricular $38^{\circ} \mathrm{C}$ ); auscultação pulmonar com crepitações ao nível da base pulmonar direita; púrpura palpável ao nível dos membros inferiores com edema associado (Figura 1); sem alterações no restante exame.

Analiticamente com anemia de doença crónica/inflamação; plaquetas normais; elevação dos marcadores inflamatórios; sedimento urinário ativo com presença de leucócitos, eritrócitos e cilindros (hialinos, celulares e granulosos); proteinúria não nefrótica; função renal e iões sem alterações; gasometria arterial normal (Tabela 1). A ecografia renal mostrou aumento da ecogenicidade do parênquima renal, sem outras alterações Na radiografia de tórax sem infiltrados no parênquima pulmonar, identificando-se 2 estruturas tubulares compatíveis com o shunt ventrículo-peritoneal e a porção remanescente do shunt ventrículo-auricular. 0 ecocardiograma transtorácico revelou duas massas localizadas na proximidade do shunt ventrículo-auricular na aurícula direita a sugerir vegetações na sua dependência (Figura 2). Assumiu-se sépsis com provável ponto de partida em infeção do shunt ventrículo-auricular e iniciou empiricamente Vancomicina e Meropenem. Isolado posteriormente Staphylococcus aureus meticilino sensível em hemoculturas.

Do estudo subsequente salienta-se positividade dos anticorpos antinucleares (ANA), anti-dsDNA e ANCA-PR3; consumo de C3 e C4; hipergamaglobulinémia com elevação da lgG e da IgM; fator reumatóide positivo e velocidade de sedimentação elevada (Tabela 1). Equacionada nesta altura a hipótese de NS.

Apesar da antibioterapia instituída, verificou-se agravamento clínico, com documentação de êmbolos sépticos pulmonares (Figura 3), pelo que foi decidido remover 0 shunt ventrículo-auricular.

Completou 6 semanas de antibioterapia com Vancomicina, tendo-se 
Figura 2. Ecocardiograma transtorácico - massa localizada na aurícula direita em proximidade com o shunt ventrículo-auricular

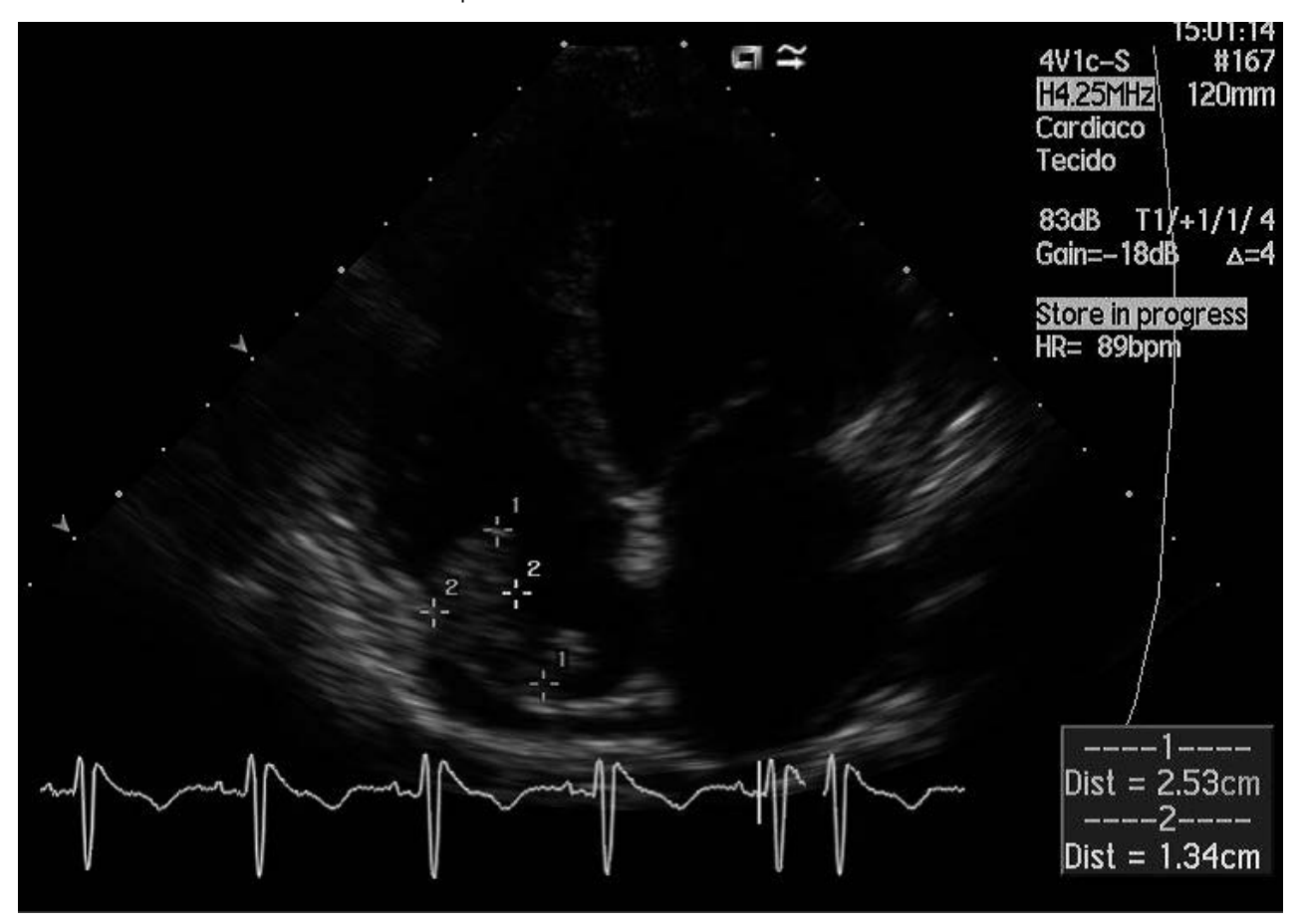

verificado uma evolução favorável com melhoria clínica (resolução das lesões purpúricas, da febre e da anorexia), analítica (incluindo normalização das alterações do sedimento urinário, do complemento e diminuição progressiva dos títulos de autoanticorpos) (Tabela 1) e ecocardiográfica (desaparecimento das vegetações).

\section{Discussão}

A NS está relacionada com a infeção subaguda/crónica de dispositivos endovasculares, principalmente de shunts ventrículo-auriculares, e assemelha-se à glomerulonefrite associada às endocardites subagudas. A infeção do shunt conduz a bacteriémias transitórias com exposição dos antigénios bacterianos e consequente produção de anticorpos, ativação do complemento e deposição dos imunocomplexos no rim4. Histologicamente, a lesão glomerular mais frequentemente encontrada é um padrão membronoproliferativo, semelhante à resultante de outras infeções bacterianas ${ }^{4}$.

A NS carece de achados clínicos e analíticos específicos e 0 seu diagnóstico exige uma elevada suspeita clínica. 0 intervalo de tempo entre a colocação do shunt e o aparecimento da NS é muito variável (5 meses a 21 anos) ${ }^{4}$. São vários os microrganismos que podem causar NS, embora os mais frequentemente implicados sejam o Staphylococcus epidermidis (70\%) e o Staphylococcus aureus (20\%) .

As manifestações clínicas habitualmente encontradas são hematúria (89\%), febre recorrente (88\%), hepatoesplenomegalia (55\%), púrpura não trombocitopénica (19\%) e hipertensão arterial $(15 \%)^{9}$. Oitenta e seis porcento dos doentes apresentam anemia, 70\% têm proteinúria, 30\% desenvolvem síndrome nefrótico e em 85 a 94\% verifica-se consumo de complemento ${ }^{9}$.

A semelhança do que acontece em outras situações de bacteriemias associadas a dispositivos intravasculares, na infeção de shunt há indicação para a remoção do mesmo; no nosso caso fez-se uma tentativa inicial de erradicação do microrganismo com antibiótico, dado o historial prévio da tentativa de remoção, sem sucesso, o que faria prever uma cirurgia complicada, morosa e de alto risco. No entanto, perante 0 agravamento clínico, com o aparecimento de êmbolos sépticos em outros órgãos, optou-se pela remoção.

Apesar do "background" imunológico indiscutivelmente presente neste caso, optou-se por priorizar o tratamento da bacteriémia a Staphylococcus aureus e não foi instituída terapêutica com corticoesteróides ou outros imunossupressores. A antibioterapia escolhida foi a vancomicina dada a história de alergia a beta-lactâmicos. A daptomicina seria também outra opção válida, uma vez que está reconhecida a sua eficácia em endocardites direitas e infeções de dispositivos intra-cardíacos e com a vantagem de não ser nefrotóxica ${ }^{10}$. Com o tratamento dirigido do Staphylococcus aureus, incluindo controlo do foco, verificou-se a resolução da glomerulonefrite bem como diminuição paulatina dos títulos de autoanticorpos anti-dsDNA e ANCA-PR3.

Na literatura, estão descritos casos de NS associadas a anticorpos ANA e a ANCA-PR3 positivos ${ }^{6,7}$. Embora o mecanismo 
Figura 3. Tomografia pulmonar a mostrar embolização séptica pulmonar.

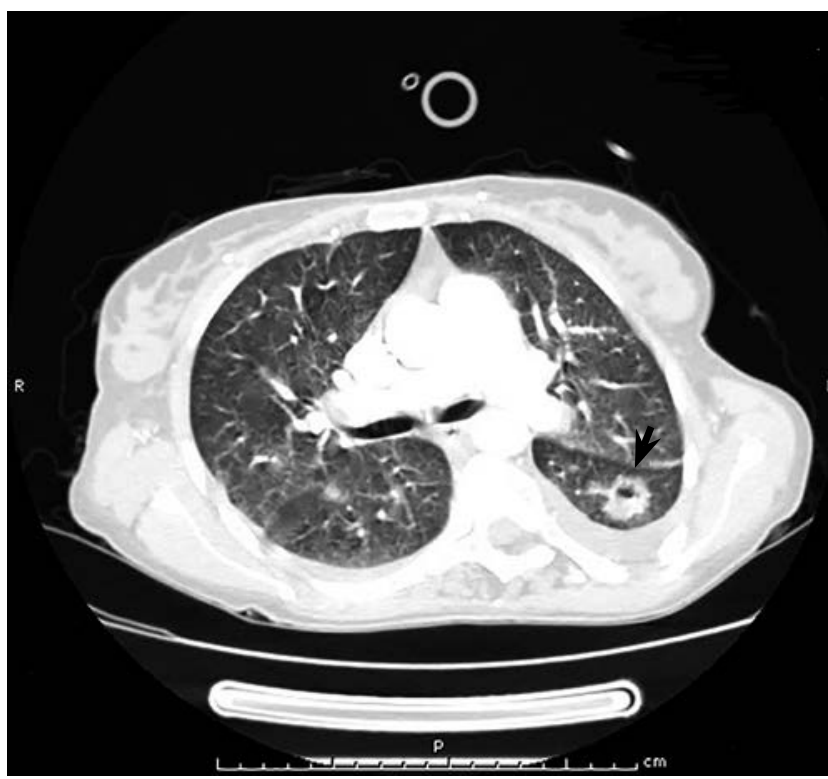

que leva ao aparecimento desses autoanticorpos e a sua persistência na presença de infeções prolongadas não esteja completamente esclarecido, pensa-se que, em doentes geneticamente suscetíveis, as infeções e outros estímulos ambientais possam desencadear respostas imunológicas através de mecanismos como a produção de citoquinas, a estimulação de toll-like receptors, a libertação de autoantigénios pelas células e tecidos lesados e o mimetismo molecular ${ }^{1}$.

Os anticorpos anti-dsDNA têm elevada especificidade para 0 diagnóstico de LES embora, raramente possam ser detetados em outras doenças autoimunes como a artrite reumatóide, a síndrome de Sjogren, a esclerose sistémica e a síndrome antifosfolipídea11. Têm importância não só no diagnóstico mas também na monitorização da atividade da doença, estando particularmente implicados na patogénese da nefrite lúpica ${ }^{12}$. Sabe-se que nem sempre são patogénicos e estão descritos casos de aumento transitório de anti-dsDNA em doentes com sépsis grave ${ }^{13}$. Adicionalmente, encontram-se relatos da sua presença em outras situações de infecção perpetuada e grave.
Attar SM et al avaliaram 212 doentes com anti-dsDNA dos quais 11 tinham infeções ${ }^{14}$. Assim, apesar dos anticorpos anti-dsDNA serem frequentemente associados ao diagnóstico/atividade do LES, deve suspeitar-se de outra doença se os critérios clínicos são discordantes e/ou o nível de autoanticorpos for equívoco.

Após revisão da literatura, tanto quanto é do nosso conhecimento este á o primeiro caso descrito da presença de anticorpos anti-dsDNA na NS.

A relação temporal, a descida dos títulos de anticorpos e 0 não aparecimento de outras alterações sugestivas de doença imunológica (por exemplo LES) indiciam uma interdependência entre o fenómeno imunológico e a infeção.

\section{Bibliografia}

1. Kivity S, Agmon-Levin N, Blank M, Shoenfeld Y. Infections and autoimmunity--friends or foes? Trends in immunology. 2009;30(8): 409-14

2. Riding AM, D'Cruz DP. A case of mistaken identity: subacute bacterial endocarditis associated with p-antineutrophil cytoplasmic antibody. BMJ Case Reports 2010;1136/bcr.09.2010.3299

3. Black JA, Chaacombe DN, Ockenden BG. Nephrotic syndrome associated with bacteraemia after shunt operations for hydrocephalus. Lancet 1965;2: 921-4

4. Haffner D, Schindera F, Aschoff A, Matthias S, Waldherr R et al. The clinical spectrum of shunt nephritis. Nephrol Dial Transplant. 1997; 12: 1143-8

5. Narchi H, Taylor R, Azmy AF, Murphy AV, Beattie TJ. Shunt nephritis. J Pediatr Surg 1988;23: 839-41

6. Iwata Y, Ohta S, Kawai K, Yamahana J, Sugimori H, Ishida Y et al. Shunt Nephritis With Positive Titers for ANCA Specific for Proteinase 3. American Journal of Kidney Diseases. 2004;43(5): e11-e15

7. Bonarek H, Bonnet F, Delclaux C, Deminière C, Précigout VD et al. Reversal of CANCA positive mesangiocapillary glomerulonephritis after removal of na infected cysto-atrial shunt. Nephol Dial Transplant. 1999;14: 1771-3

8. Kavanaugh AF, Solomon DH, American College of Rheumatology Ad Hoc Committee on Immunologic Testing Guidelines. Guidelines for immunologic laboratory testing in the rheumatic diseases: anti-DNA antibody tests. Arthritis Rheum. 2002;47(5): 546

9. Balogun RA, Palmisano J, Kaplan A, Khurshid $H$, YamaseH et al. Shunt nephritis from Propionibacterium acnes in a solitary kidney. American Journal of Kidney Diseases. 2001;38: E18

10. Durante-Mangoni E, Casilo R, Caianiello C, Mattucci I, Pinto D et al. High-Dose Daptomycin for Cardiac Implantable Electronic Device-Related Infective Endocarditis. CID.2012;54(3): 347-54

11. Kavanaugh AF, Solomon DH, American College of Rheumatology Ad Hoc Committee on Immunologic Testing Guidelines. Guidelines for immunologic laboratory testing in the rheumatic diseases: anti-DNA antibody tests. Arthritis Rheum. 2002;47(5): 546-55.

12. Borchers AT, Leibushor N, Cheema GS, Shoenfeld Y, Gershwin ME. Lupus nephritis: a critical review. Autoimmun Rv. 2012;12(2): 174-94.

13. Isenberg D. Anti-dsDNA antibodies: still a useful criterion for patients with systemic lupus erythmatosus?. Lupus. 2004; 13: 881-5.

14. Attar SM, Koshak EA. Medical conditions associated with a positive anti-doublestranded deoxyribonucleic acid. Saudi Med J. 2010;31(7): 781-7. 